\title{
The effect of photo-irradiation on the growth and ingredient composition of young green barley (Hordeum vulgare)
}

\author{
Ryota Koga ${ }^{1,2}$, Tianxiao Meng ${ }^{1}$, Eriko Nakamura ${ }^{1}$, Chizuru Miura ${ }^{1}$, Nobuto Irino ${ }^{1,2}$, \\ Hari Prasad Devkota ${ }^{3}$, Shoji Yahara ${ }^{3}$, Ryuichiro Kondo ${ }^{1^{*}}$ \\ ${ }^{1}$ Department of Agro-Environmental Science, Faculty of Agriculture, Kyushu University, Fukuoka, Japan; \\ *Corresponding Author: ryukondo@agr.kyushu-u.ac.jp \\ ${ }^{2}$ Asahi Ryokuken Co., Ltd., Fukuoka, Japan \\ ${ }^{3}$ Graduate School of Pharmaceutical Sciences, Kumamoto University, Kumamoto, Japan
}

Received 5 February 2013; revised 15 March 2013; accepted 13 April 2013

Copyright (C) 2013 Ryota Koga et al. This is an open access article distributed under the Creative Commons Attribution License, which permits unrestricted use, distribution, and reproduction in any medium, provided the original work is properly cited.

\begin{abstract}
We clarified that photo-irradiation of young green barley from three different light sources, natural light, $100 \%$ red light-emitting diodes (R-LEDs), and a mixture of $90 \%$ red-LEDs $+10 \%$ blue-LEDs (RB-LEDs), had significantly different results in growth degree (weight and height) and in components of young green barley. Barley that has sprouted for 15 days after germination did not show any apparent difference in height in response to irradiation by the three tested light sources, but by the $20^{\text {th }}$ day of sprouting the height showed a positive effect by R-LEDs irradiation. By 15 days of sprouting the barley had achieved the heaviest weight by natural light irradiation, while the barley irradiated by R-LEDs had made remarkable progress at 20 days of sprouting. On the other hand, the irradiation by RB-LEDs showed a suppressive tendency after 15 days or more. The amino acid content, as indicated by dry weight conversion, was greatest in the barley irradiated by RB-LEDs, followed by R-LEDs, and natural light, which showed that LEDs irradiation is effective. In addition, four cyanogenic glucosides were isolated, identified, and quantified, as they are components frequently assessed in barley research. With regard to vitamin E, R-LEDs irradiation increased Y-tocopherol. Our results indicate that irradiation by LEDs would be effective for the enhancement of the functionality of young green barley.
\end{abstract}

Keywords: Hordeum Vulgare; LEDs; Cyanogenic
Glucosides; Amino Acid; Tocopherol; SEM

\section{INTRODUCTION}

Barley is one of the major cereal grains and has been cultivated especially as a staple grain. It has begun to receive much attention since the beneficial effect of young green barley leaves was determined through the presence of potent antioxidants. Barley contains phenolic compounds as antioxidants as well as rich vitamins, and it can be cultivated in less than one month. Examining the antioxidant activity of extracts is a major research theme for young green barley leaves, and the research has revealed that the main components of potent antioxidant activities are flavonoids such as saponarin and lutonarin [1-4].

Since barley leaves are an important product as food and forage, many studies for the stress from environment in cultivating barley leaves have been reported [5-7]. The harvest period for barley leaves and their components have been the focuses of some studies. Regarding the harvest period, Paulickova et al. reported that the barley that has sprouted for 20 days had the highest levels of amino acid, vitamin C, and polyphenolic compounds [8], which was the barley at decimal code 29 for the growth stages of cereals [9].

The influence of the choice of light source on the content and morphology of barley has been reported, especially in the case of using various types of light-emitting diodes (LEDs), which has been developed in these days. This research aims to examine crop growing conditions and the growth parameters of barley leaves cultivated under LEDs radiation. The results indicate that B-LEDs radiation suppresses height progress and R-LEDs radia- 
tion suppresses weight progress [10]. There is also evidence that growing barley leaves with different light sources affects secondary metabolic products such as phenolic compounds and vitamin $\mathrm{C}$. The R-LEDs radiation can enrich phenolic compounds and vitamin $\mathrm{C}$ contents more than can $\mathrm{R}+\mathrm{B}-\mathrm{LED}$ radiation [11]. Another investigation indicated that the addition of B-LEDs to R-LEDs influenced the contents of phenolic compounds and vitamin $\mathrm{C}$ and enhanced antioxidant activity. Supplementing R-LEDs with B-LEDs resulted in a $16 \%$ increase in phenolic acid and vitamin $\mathrm{C}$ contents compared to the use of R-LEDs only. Based on these results, Urbonaviciute et al. suggested that R-LEDs radiation caused light stress in plants [12].

With regard to the cyanogenic glucosides contents, a relation between stress and nitrogen levels in barley has been reported $[13,14]$. Cyanogenic glucosides are present in many plants, and their ability to liberate toxic $\mathrm{HCN}$ offers an immediate chemical defense response to herbivores and pathogens causing damage to the plant tissue [15]. This phenomenon has mainly been studied in sorghum $[16,17]$.

In the present study, we focused on the effects of three light sources on the development of barley during the cultivation of nutrient-rich young green barley leaves.

\section{MATERIALS AND METHODS}

\subsection{Plant Material and Growth Conditions}

Two-rowed barley (Hordeum vulgare f. distichon) Nishinohoshi was harvested in 2011. Seeds were sown in planters $\left(41 \times 20 \mathrm{~cm}\right.$, soil area $\left.820 \mathrm{~cm}^{2}\right)$ containing organic fertilizers (SHOEI, Myazaki, Japan) in a biotron growth chamber at $15^{\circ} \mathrm{C}-20^{\circ} \mathrm{C}, 70 \%$ relative humidity. LEDs (Model 3LH-256; Nippon Medical and Chemical Instrument Co., Ltd., Japan) tested in the biotron chamber were shaded by an aluminum shade sheet to simulate sun-screening.

Young green barley plants were divided into three groups, the natural light group (control group), the group grown under $100 \%$ red LEDs light (R-LEDs), and the group grown under a mixture of $90 \%$ red $+10 \%$ blue LEDs lights (RB-LEDs) (treatment groups). Each group was harvested on the $5^{\text {th }}, 10^{\text {th }}, 15^{\text {th }}$, and $20^{\text {th }}$ day after germination, and the plant height and weight were quantified as growth parameters.

\subsection{Determination of Photon Flux Density}

The three light sources were natural light, R-LEDs, and RB-LEDs. Red and blue LEDs have a peak emission at $660 \mathrm{~nm}$ and $445 \mathrm{~nm}$, respectively.

Natural light planters were placed on shelves $25 \mathrm{~cm}$ and $115 \mathrm{~cm}$ above the ground in the biotron. Each LEDs light source was set at $39 \mathrm{~cm}$ from the surface of the planter soil. Photon flux density was measured (Model101EG, Nippon Medical and Chemical Instrument Co., Ltd., Japan) at soil level of each planter. The light intensity of natural light was $119.5-140.5 \mu \mathrm{mol} \cdot \mathrm{m}^{-2} \cdot \mathrm{s}^{-1}$ (rainy or overcast days) or about $1280 \mu \mathrm{mol} \cdot \mathrm{m}^{-2} \cdot \mathrm{s}^{-1}$ (clear day), and $54.2 \mu \mathrm{mol} \cdot \mathrm{m}^{-2} \cdot \mathrm{s}^{-1}$ and $52.3 \mu \mathrm{mol} \cdot \mathrm{m}^{-2} \cdot \mathrm{s}^{-1}$ for R-LEDs and RB-LEDs, respectively.

\subsection{Scanning Electron Microscope Analysis of Adhesive Interfacial Microstructure}

Samples of young green barley grown under each of the three light sources, which were harvested on the $15^{\text {th }}$ day after germination and freeze dried, were glued to aluminium stubs with adhesive tape and kept at room temperature for $30 \mathrm{~min}$. After that, samples were directly sputtered with gold palladium in a Sputter Coater (SC7620) and examined using a scanning electron microscope (SEM, JSM-5600LV, JEOL Co., Ltd., Japan).

\subsection{Determination of Amino Acids Composition}

Amino acids (except for tryptophan) in the young green barley plants on the $15^{\text {th }}$ day after germination cultivated under the three light sources were determined by a JLC-500/V automatic amino acid analyzer (JEOL Co., Ltd., Japan), and tryptophan in the young green barley was measured by an LC-20AD solvent delivery unit (Shimadzu Corporation, Ltd., Japan). The sample dry weight of natural light plants $(\mathrm{n}=412)$ was $9.7 \mathrm{~g}$, that of R-LEDs plants $(\mathrm{n}=377)$ was $8.3 \mathrm{~g}$, and that of RB-LEDs plants $(\mathrm{n}=336)$ was $8.9 \mathrm{~g}$.

\subsection{Determination of Vitamins $C$ and $E$}

Vitamin C (ascorbic acid) content on the 20th day after germination for plants cultivated under three light sources was evaluated using a spectrophotometric method [18]. Two to six grams of young green barley was homogenized in $50 \mathrm{~mL}$ of $5 \%$ metaphosphoric acid and centrifuged. One millilitre of extract was mixed with 1 $\mathrm{mL}$ of $5 \%$ metaphosphoric acid, $200 \mu \mathrm{L}$ of $0.2 \% 2,6-$ dichlorophenol-indophenol and $2 \mathrm{~mL}$ of $2 \%$ thiourea- $5 \%$ metaphosphoric solution. As an oxidative reaction 0.5 $\mathrm{mL}$ of $2 \%$ 2,4-dinitrophenyl-hydrazine $4.5 \mathrm{~mol} / \mathrm{L}$ sulfuric acid solution was added, and the mixture was allowed to stand for 16 hours at $38^{\circ} \mathrm{C}-42^{\circ} \mathrm{C}$. Then, $3 \mathrm{~mL}$ of ethyl acetate was added, and the mixture was shaken for about $60 \mathrm{~min}$. The supernatants were analyzed using the LC20AT (Shimadzu Co., Ltd.) system equipped with a Senshupak Silica-1100-N column (Senshu Scientific Co., Ltd.) maintained at $35^{\circ} \mathrm{C}$. Extract was eluted in the mobile phase (ethyl acetate/hexane/acetic acid/water $=60$ / $40 / 5 / 0.05$ ) at a flow rate of $1.5 \mathrm{~mL} / \mathrm{min}$. The absorbance of the eluent was measured at $495 \mathrm{~nm}$. 
The alpha, beta, gamma, and delta tocopherols $(\alpha-\mathrm{T}$, $\beta$-T, $\gamma$-T, and $\delta$-T, respectively) content of barley on the $20^{\text {th }}$ day after germination cultivated under the three light sources was evaluated according to the method of Samuoliene et al. [18] using liquid chromatography (LC20AT, Shimadzu Scientific Instruments) on YMC-Pack SIL-06 S-5 $\mu$ M particle size, $250 \times 4.6 \mathrm{~mm}$ (YMC Co., Ltd.). Young green barley was extracted using $0.3 \mathrm{~g}$ pyrogallol, $2 \mathrm{~mL}$ of $10 \mathrm{~g} / \mathrm{L}$ sodium chloride solution, and 10 $\mathrm{mL}$ of ethanol (approximately $1-2.5 \mathrm{~g}$ of sample/12 $\mathrm{mL}$ of solvent) and $2 \mathrm{~mL}$ of $600 \mathrm{~g} / \mathrm{L}$ potassium hydroxide. The mixture was boiled and then refluxed for $30 \mathrm{~min}$ at $70^{\circ} \mathrm{C}$. Next, the mixture was extracted in $20 \mathrm{~mL}$ of 10 $\mathrm{g} / \mathrm{L}$ sodium chloride solution, then $14 \mathrm{~mL}$ of hexane/ isopropanol/ethyl acetate $(9 / 1.5 / 1)$ was added, and the mixture was centrifuged (5 min, $1500 \mathrm{rpm})$ three times and filtrated through a $0.45-\mu \mathrm{M}$ PTFE membrane syringe filter. The liquid chromatography LC-20AT system, equipped with an RF-10A fluorescence detector (Shimadzu Co., Ltd. Japan) was used for analysis. The peak was detected using an excitation wavelength of 298 $\mathrm{nm}$ and an emission wavelength of $325 \mathrm{~nm}$. The mobile phase was hexane/isopropanol/acetic acid (1000/6/5 with butylated hydroxytoluene), and the flow rate was 1.5 $\mathrm{mL} / \mathrm{min}$.

\subsection{Extraction and Isolation of Cyanogenic Glucosides}

The young green barley cultivated under three light sources was extracted with $30 \%$ methanol, and extracts were subjected to MCI gel CHP-20P (75 - $150 \mu \mathrm{m}$, Mitsubishi Kasei Co., Japan) column chromatography and eluted with water and methanol. Methanol-eluted fractions were then subjected to ODS column chromatogramphy and eluted with $5 \%, 6 \%, 7 \%, 8 \%, 9 \%, 11 \%$, $13 \%, 15 \%$, and $100 \%$ methanol. Epiheterodendrin $(1,39$ $\mathrm{mg}$ ), osmaronin $(2,31 \mathrm{mg})$, sutherlandin $(3,39 \mathrm{mg})$ and epidermin, $(4,33 \mathrm{mg})$ were obtained from the fractions eluted with $5 \%$ - 9\% methanol. Structures of these compounds were elucidated on the basis of ${ }^{1} \mathrm{H}-\mathrm{NMR}$ (JEOL, $500 \mathrm{MHz}$ ) and ${ }^{13} \mathrm{C}-\mathrm{NMR}$ (JEOL, $125 \mathrm{MHz}$ ) spectral data and compared with literature values $[14,19]$.

\section{RESULTS}

\subsection{Effect of Light Irradiation on Growth of Young Green Barley}

The height of young green barley that had sprouted for 15 days after germination did not show significant difference in response to irradiation by the three tested light sources, natural light, R-LEDs, and RB-LEDs, but by the $20^{\text {th }}$ day after germination the plants showed a 1.6-fold increase by R-LEDs and a 1.4-fold increase by RB-LEDs compared with natural light irradiated barley. These re- sults indicated that R-LEDs irradiation is the most effecttive light for growth in height of barley leaves at the $20^{\text {th }}$ day after germination (Figure 1).

Regarding the weight of barley plants at the $15^{\text {th }}$ day after germination under the three light growth condition, the barley under natural light irradiation had achieved the heaviest weight. However, on the $20^{\text {th }}$ day, R-LEDs irradiated barley was extended and had gained significantly more weight compared with barley irradiated by RBLEDs, which showed a suppressive action (Figure 2). We can conclude that LEDs are very effective for promoting growth in height and also in weight of barley leaves, especially R-LEDs at the $20^{\text {th }}$ day after germination (Figures 1 and 2).

\subsection{Scanning Electron Microscopeobservation of Interfacial Structure}

On the $15^{\text {th }}$ day after germination, young green barley leaves were freeze-dried and prepared for observation with a scanning electron microscope (SEM) (original magnification: $500 \times$; Scale bar $=50 \mu \mathrm{M})$. The density of organization of leaves resulted in the order of natural light $>$ R-B LEDs > R-LEDs (Figure 3). The differences in the organization chart were compatible with those for moisture content (RB-LEDs $=$ R-LEDs $>$ natural light) (Table 1), suggesting that LEDs succeeded in making young green barley fresh. The electron micrograph shows a fresh barley leaf grown under LEDs illumination, which has more cavities that will hold moisture than in the case of growing under natural light.

\subsection{Effects of Photo-Irradiation on the Amino Acid Contents and Composition}

Table 1 shows the amino acid composition of freezedried barley leaves. Compared to natural light irradiated barley, the amino acid content in plants grown under R-LEDs increased $40 \%-50 \%$ and that in plants grown under RB-LEDs increased 50\% - 60\%. This result shows that LEDs light sources are effective in increasing amino acid contents. A comparison between plants grown under R-LEDs and those grown under RB-LEDs confirmed that a mixture of R-LEDs and B-LEDs was more effective than $100 \%$ R-LEDs only or natural light, which was the same as in the case of Triplerospermum japonicum [20]. Regarding the amino acid composition, the contents of glutamic acid, aspartic acid, and leucine were high, while those of methionine, histidine, and cystine were low (data not shown), which was the same tendency reported by Pauličková et al. [8].

As shown in Table 2, the nitrogen content in amino acids was in the order of RB-LEDs $>$ R-LEDs $>$ natural light. This clarified that LEDs irradiation increased the 


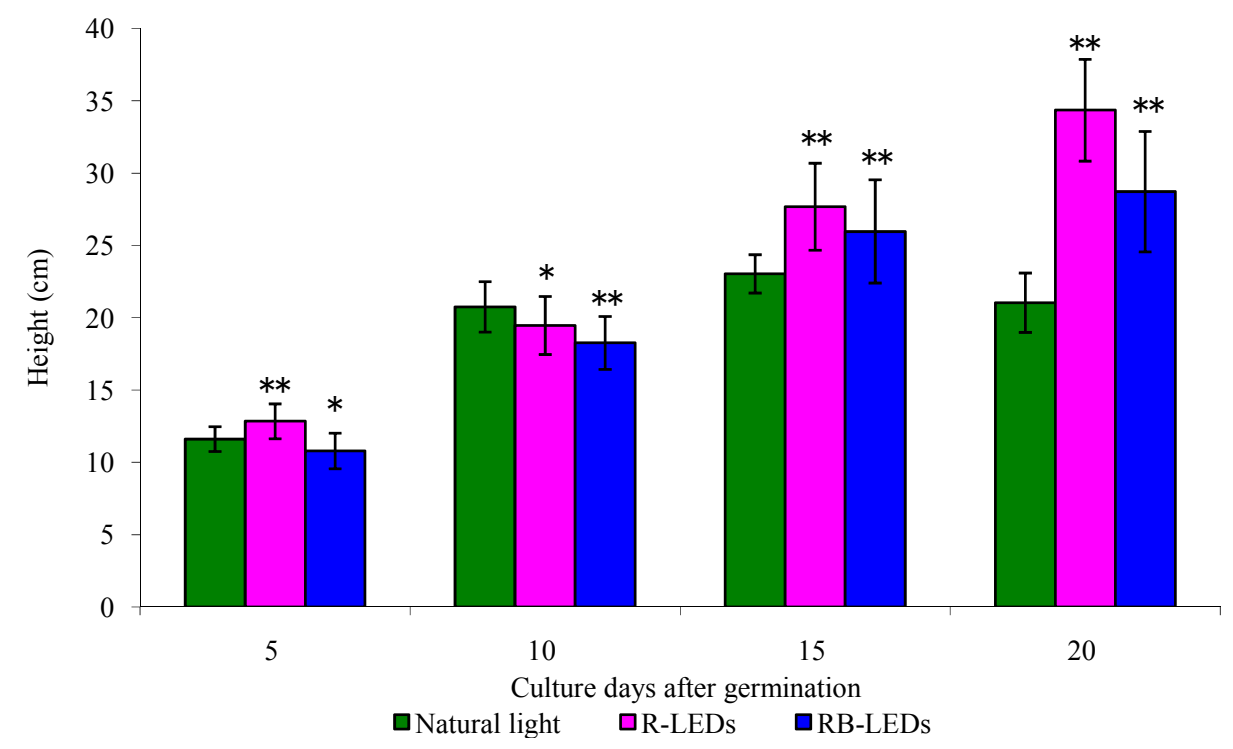

Figure 1. The effect in height by natural light and LEDs light irradiation on the growth of young green barley $\left(n=20\right.$, mean \pm standard deviation, significantly different at ${ }^{* *} \mathrm{p}<0.01$ and ${ }^{*} \mathrm{p}<0.05$ vs. natural light, according to $t$-test).

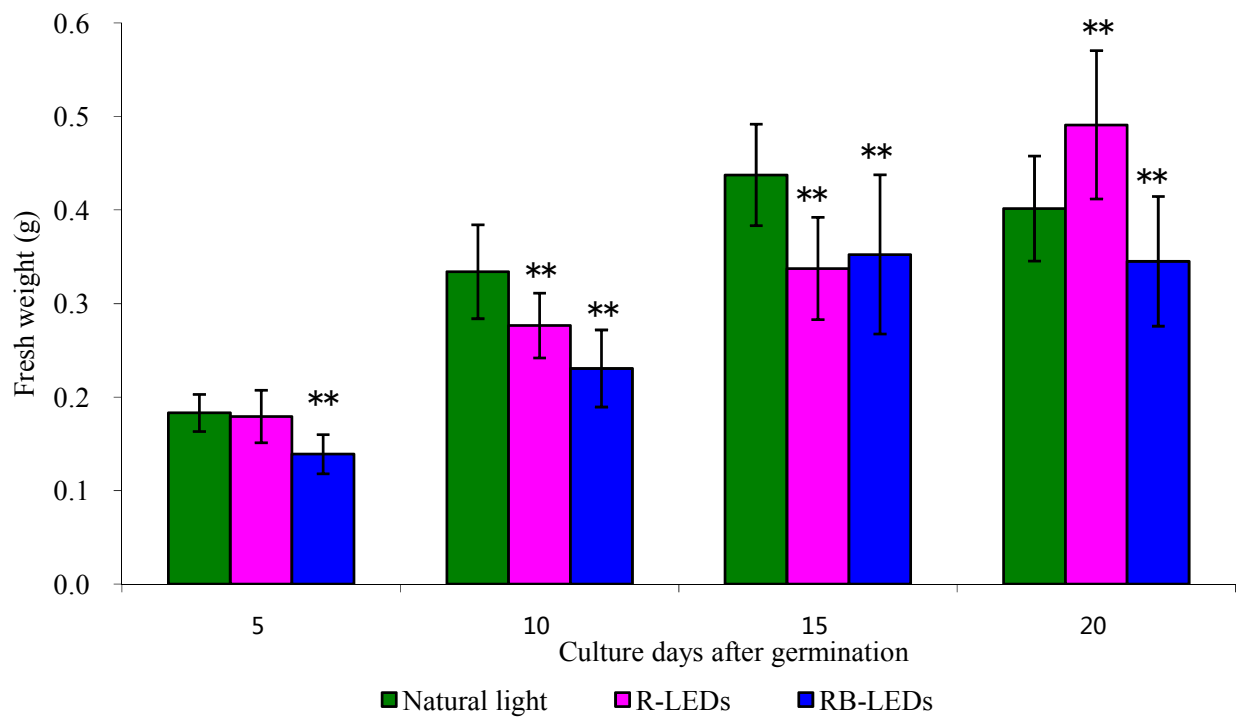

Figure 2. The effect in weight by natural light and LEDs light irradiation on the growth of young green barley $\left(n=20\right.$, mean \pm standard deviation, significantly different at ${ }^{* *} \mathrm{p}<0.01$ and ${ }^{*} \mathrm{p}<0.05$ vs. natural light, according to $t$-test).
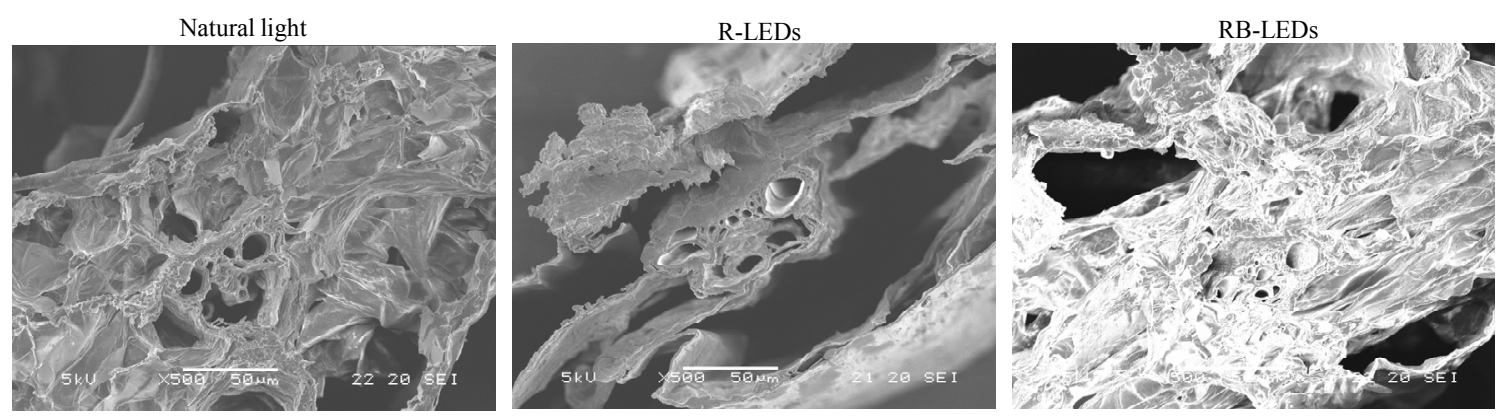

Figure 3. SEM observation interfacial of structure of young green barley leaves grown under three light sources (original magnification: $500 \times$; scale bar was $50 \mu \mathrm{M}$ ). 
Table 1. Changes in amino acid compositions of young green barley leaves grown under three light sources.

\begin{tabular}{|c|c|c|c|c|c|c|}
\hline & \multicolumn{6}{|c|}{ Amino acid contents ( $\mathrm{g} / 100 \mathrm{~g}$ dry weight) } \\
\hline & \multirow{2}{*}{ Natural light } & \multirow{2}{*}{ R-LEDs } & \multirow{2}{*}{ RB-LEDs } & R-LEDs & RB-LEDs & RB-LEDs \\
\hline & & & & Natural light & Natural light & R-LEDs \\
\hline Arginine & 0.75 & 1.08 & 1.16 & 1.4 & 1.6 & 1.1 \\
\hline Lysine & 0.89 & 1.24 & 1.34 & 1.4 & 1.5 & 1.1 \\
\hline Histidine & 0.31 & 0.46 & 0.48 & 1.5 & 1.6 & 1.0 \\
\hline Phenylalanine & 0.73 & 0.99 & 1.08 & 1.4 & 1.5 & 1.1 \\
\hline Tyrosine & 0.49 & 0.72 & 0.77 & 1.5 & 1.6 & 1.1 \\
\hline Leucine & 1.13 & 1.54 & 1.68 & 1.4 & 1.5 & 1.1 \\
\hline Isoleucine & 0.57 & 0.78 & 0.85 & 1.4 & 1.5 & 1.1 \\
\hline Methionine & 0.24 & 0.34 & 0.38 & 1.4 & 1.6 & 1.1 \\
\hline Valine & 0.79 & 1.09 & 1.18 & 1.4 & 1.5 & 1.1 \\
\hline Alanine & 0.93 & 1.26 & 1.39 & 1.3 & 1.5 & 1.1 \\
\hline Glycine & 0.77 & 1.07 & 1.15 & 1.4 & 1.5 & 1.1 \\
\hline Proline & 0.67 & 1.01 & 1.09 & 1.5 & 1.6 & 1.1 \\
\hline Glutamic acid & 1.43 & 2.07 & 2.28 & 1.5 & 1.6 & 1.1 \\
\hline Serine & 0.63 & 0.96 & 1.03 & 1.5 & 1.6 & 1.1 \\
\hline Threonine & 0.66 & 0.92 & 0.97 & 1.4 & 1.5 & 1.1 \\
\hline Aspartic acid & 1.27 & 1.93 & 2.10 & 1.5 & 1.7 & 1.1 \\
\hline Tryptophan & 0.29 & 0.35 & 0.42 & 1.2 & 1.4 & 1.2 \\
\hline Cystine & 0.19 & 0.23 & 0.25 & 1.2 & 1.3 & 1.1 \\
\hline Moisture content $(\%)$ & 88.0 & 92.6 & 92.1 & & & \\
\hline
\end{tabular}

nitrogen content in young green barley.

\subsection{Vitamin $C$ and $E$ Contents}

The amount of vitamin $\mathrm{C}$ in barley leaves cultivated under three different light sources was in the order of natural light $>$ RB-LEDs $>$ R-LEDs (Table 3). The barley leaves irradiated by LEDs contained less than half of the vitamin $\mathrm{C}$ content of natural light irradiated barley, by dry weight. Our result is opposite to Urbonaviciute's report, which suggested that irradiation with $84 \%$ RLEDs $+16 \%$ B-LEDs raised the vitamin C content [12]. There was no significant difference in the total vitamin $\mathrm{E}$ content between natural light and R-LEDs illumination by dry weight; however, the total vitamin $\mathrm{E}$ content in RB-LEDs irradiated barley decreased to 65\% compared to that in barley irradiated by natural light (Table 3). It was significant that $\gamma$-tocopherol in R-LEDs irradiated barley was $50 \%$ greater than the level in plants irradiated by the other light sources.

\subsection{Isolation and Identification of Cyanogenic Glucosides}

Four kinds of cyanogenic glucoside were isolated and identified from methanol extract of young green barley irradiated by natural light, R-LEDs, and RB-LEDs. NMR identified them as: 1) epiheterodendrin, 2) osmaronin, 3) sutherlandin, and 4) epidermin, and this result is almost the same as Pourmohsen's report [19]. These four cyanogenic glucosides corresponded to four cyanogenic glucosides out of 5 that Pourmohseni et al. isolated; we were not able to isolate dihydroosmaronin. According to Nielsen's report [14], dihydroosmaronin represents only $2 \%-4 \%$ of the cyanogenic glucosides content.

The cyanogenic glucosides content is shown in Table 4. The result shows that the total content of cyanogenic glucosides occured in the order natural light $>$ RB-LEDs $>$ R-LEDs, and R-LEDs suppressed the composition of osmaronin, compared to the other two lighting conditions. The ratio of each cyanogenic glucoside in the composition of barley leaves irradiated by R-LEDs was near to 
Table 2. Nitrogen contents of young green barley leaves grown under three light sources.

\begin{tabular}{|c|c|c|c|c|c|c|}
\hline & \multicolumn{6}{|c|}{ Nitrogen contents ( $\mathrm{g} / 100 \mathrm{~g}$ dry weight) } \\
\hline & \multirow{2}{*}{ Natural light } & \multirow{2}{*}{ R-LEDs } & \multirow{2}{*}{ RB-LEDs } & R-LEDs & RB-LEDs & RB-LEDs \\
\hline & & & & Natural light & Natural light & R-LEDs \\
\hline Arginine & 0.29 & 0.42 & 0.45 & 1.4 & 1.6 & 1.1 \\
\hline Lysine & 0.21 & 0.29 & 0.31 & 1.4 & 1.5 & 1.1 \\
\hline Histidine & 0.10 & 0.15 & 0.16 & 1.5 & 1.6 & 1.0 \\
\hline Phenylalanine & 0.07 & 0.10 & 0.11 & 1.4 & 1.5 & 1.1 \\
\hline Tyrosine & 0.05 & 0.07 & 0.07 & 1.5 & 1.6 & 1.1 \\
\hline Leucine & 0.15 & 0.20 & 0.22 & 1.4 & 1.5 & 1.1 \\
\hline Isoleucine & 0.07 & 0.10 & 0.11 & 1.4 & 1.5 & 1.1 \\
\hline Methionine & 0.03 & 0.04 & 0.04 & 1.4 & 1.6 & 1.1 \\
\hline Valine & 0.11 & 0.16 & 0.17 & 1.4 & 1.5 & 1.1 \\
\hline Alanine & 0.18 & 0.24 & 0.27 & 1.3 & 1.5 & 1.1 \\
\hline Glycine & 0.17 & 0.24 & 0.26 & 1.4 & 1.5 & 1.1 \\
\hline Proline & 0.10 & 0.15 & 0.16 & 1.5 & 1.6 & 1.1 \\
\hline Glutamic acid & 0.16 & 0.24 & 0.26 & 1.5 & 1.6 & 1.1 \\
\hline Serine & 0.10 & 0.16 & 0.17 & 1.5 & 1.6 & 1.1 \\
\hline Threonine & 0.09 & 0.13 & 0.14 & 1.4 & 1.5 & 1.1 \\
\hline Aspartic acid & 0.16 & 0.25 & 0.27 & 1.5 & 1.7 & 1.1 \\
\hline Tryptophan & 0.05 & 0.06 & 0.07 & 1.2 & 1.4 & 1.2 \\
\hline Cystine & 0.03 & 0.03 & 0.04 & 1.2 & 1.3 & 1.1 \\
\hline Total nitrogen & 2.1 & 3.0 & 3.3 & & & \\
\hline
\end{tabular}

Table 3. Vitamin C (ascorbic acid) and E (tocopherol) contents of young green barley grown under three light sources.

\begin{tabular}{cccc}
\hline & \multicolumn{3}{c}{ Vitamin contents $^{*}$ (mg/100g dry weight) } \\
\cline { 2 - 4 } & Natural light & R-LEDs & 170 \\
\hline Total ascorbic acid & 380 & 150 & 11 \\
$\alpha$-tocopherols & 20 & 14 & 6 \\
$\gamma$-tocopherols & 6 & 9 & 6 -LEDs \\
\hline
\end{tabular}

Table 4. Contents of cyanogenic glucoside (CGs) of young green barley grown under three light sources.

\begin{tabular}{cccc}
\hline & & CGs contents (mg/100g fresh weight) & RB-LEDs \\
\cline { 2 - 4 } & Natural light & R-LEDs & 39 \\
\hline Epiheterodendrin (1) & 53 & 31 & 31 \\
Osmaronin (2) & 47 & 15 & 31 \\
Sutherlandin (3) & 24 & 44 & 22 \\
Epidermin (4) & 30 & 116 & 123 \\
Total CGs & 154 & 26 & 22 \\
\hline
\end{tabular}


that given in Nielsen's report [14].

The quantification of total nitrogen content in young green barley on the $15^{\text {th }}$ day after germination cultivated under three light sources is shown in Figure 4. The nitrogen contents occurred in the order of R-LEDs $>$ RB-LEDs $>$ natural light, which indicates that R-LEDs irradiated barley gained $25 \%$ more nitrogen than that occurring in barley irradiated by natural light. Also, Table 5 shows a comparison of the amount of total nitrogen and amino-type nitrogen from amino acids. The results of this study clarified that the amino-type nitrogen accumulated under LEDs irradiation. In particular, aminotype nitrogen levels were highest under RB-LEDs irradiation.

\section{DISCUSSION}

Regarding the impact of photo-irradiation by three different lights sources on young green barley, our study results showed that LEDs irradiation, especially by R-LEDs, promoted plant height, compared to the effect of growing under natural light. In the cultivation of barley, R-LEDs radiation plays a role of promoter, instead of photostressor which Urbonaviciute et al. have suggested in their report [12]. Regarding weight, R-LEDs irradiated barley exhibited dramatic weight gain at 20 days of sprouting after germination, while RB-LEDs irradiated barley gained less weight, which appears to indicate that

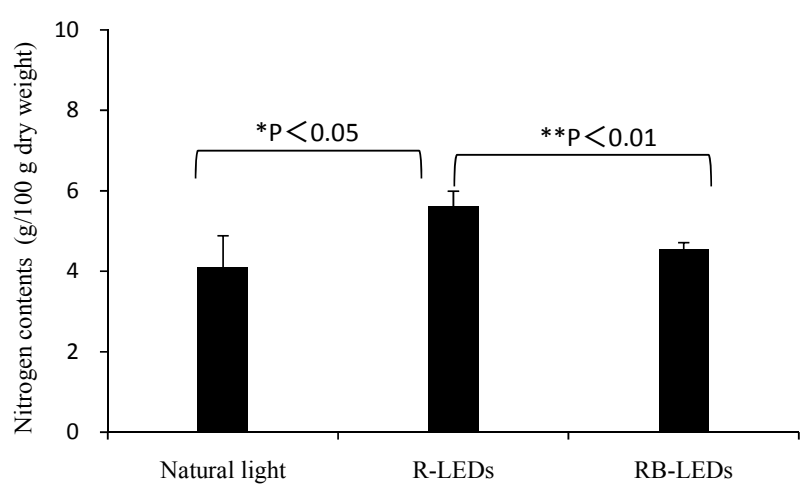

Figure 4. Quantification of total nitrogen of young green barley grown under three light sources $(n=3$, mean \pm standard deviation, significantly different at ${ }^{* *} \mathrm{p}<0.01$ and ${ }^{*} \mathrm{p}<0.05$, according to $t$-test).

Table 5. Nitrogen contents of young green barley grown under three light soures.

\begin{tabular}{cccc}
\hline & \multicolumn{3}{c}{ Nitrogen contents (g/100g dry weight) } \\
\cline { 2 - 4 } & Natural light & R-LEDs & RB-LEDs \\
\hline Total nitrogen & 4.1 & 5.6 & 4.5 \\
Amino-type nitrogen & 2.1 & 3.0 & 3.3 \\
Amino-type/total nitrogen (\%) & 51.2 & 53.6 & 73.3 \\
\hline
\end{tabular}

B-LEDs irradiation suppresses weight gain. According to Goins et al., in the case of wheat, there was no difference in height at 25 days of cultivation between the wheat grown under $100 \%$ R-LEDs and that grown under RLEDs supplemented with 10\% blue fluorescent light (BF: 400 - $500 \mathrm{~nm}$ ), however, wheat under 100\% R-LEDs had grown rapidly by the $40^{\text {th }}$ day. Regarding wheat weight, supplementation with $10 \% \mathrm{BF}$ radiation was effective from the primary stage of germination, and on the $25^{\text {th }}$ day the wheat was 1.6-fold heavier than the wheat grown under $100 \%$ R-LEDs [21]. Our present study showed that the height of barley was approximately the same as that of the wheat in Goins's report, but regarding the weight, the result was the opposite, indicating that even among similar plant types, the reactions to light irradiation vary. Furthermore, there are some other reports that far infrared rays are effective for growing barley leaves [22,23].

In this study we isolated and identified four kinds of cyanogenic glucoside, and they corresponded to 4 of 5 cyanogenic glucosides isolated by Pourmohseni et al. from young barley leaves just after budding [19]. Cyanogenic glucosides in plants are known to be derived from six kinds of amino acid as the precursor: L-valine, L-isoleucine, L-leucine, L-phenylalanine, L-tyrosine, and cyclopentenyl-glysine [24]. Regarding barley leaves, it was reported that 5 kinds of cyanogenic glucoside were derived from L-Leucine, the precursor, and $90 \%$ of cyanogenic glucosides were concentrated in epidermic cells of the leaves [25].

Nielsen et al. quantified each cyanogenic glucoside in the biosynthesis pathway, and their ratios were sutherlandin 3) 40\%, epidermin 4) 30\%, epiheterodendrin 1) less than $20 \%$, osmaronin 2), 10\%, dihydroosmaronin 5) $2 \%-4 \%$ [14].

Our determination of the amount of each cyanogenic glucoside in barley leaves grown by irradiating them under three different types of light source resulted in the order natural light $>$ RB-LEDs $>$ R-LEDs, as shown in Table 4. Since this is the ratio of cyanogenic glucosides in the whole barley plant, including the leaves and stem, it might be different from Nielsen's ratio for the 4 cyanogenic glucosides in the leaves only. In a study of infection by barley powdery mildew fungus, Nielsen et al. proved that there is no liberation of $\mathrm{HCN}$ from cyanogenic glucosides. Also, according to Forslund's experiment [13], one of the possible roles for cyanogenic glucosides is as nitrogen storage compounds. In the case of sorghum, while studying the biosynthesis of cyanogenic glucosides, Blumenthal et al. observed that $\mathrm{H}^{14} \mathrm{CN}$ fed to sorghum seedlings was extensively and specifically converted to the amide carbon atom of asparagines [26], and there are biosynthesis pathways of cyanogenic glucosides for accumulating nitrogen [15].

In our study, the amino acids contents of young green 
barley increased 1.4-fold under R-LEDs irradiation and 1.6-fold under RB-LEDs irradiation, compared to that of natural light. Irradiation using LEDs, especially RBLEDs, was an effective way to make the barley leaves nutritionally rich. This suggests that various combinations of LEDs have the potential to produce more nutriatious barley leaves than those grown under natural light.

In addition, the amount of nitrogen in amino acid increased 1.4-fold under R-LEDs irradiation and 1.5-fold under RB-LEDs irradiation (Table 2). On the other hand, under R-LEDs irradiation the total cyanogenic glucosides content was reduced to 0.7 times the amount under natural light, and under RB-LEDs irradiation it was reduced to 0.8 times the amount under natural light (Table 4). Compared to the contents of nitrogen in whole barley, amino-type nitrogen in amino acids was increased under LEDs irradiation, especially that by RB-LEDs (Table 5).

Though the biosynthesis pathway from cyanogenic glucosides to amino acids has not yet been clarified in barley, our results indicate that LEDs radiation, especially by RB-LEDs, encourages the conversion from cyanogenic glucosides to amino-type nitrogen in amino acids.

Vitamin C content in LEDs irradiated barley, which is a secondary metabolite of barley leaves, was decreased compared with natural light irradiated barley; however, when R-LEDs irradiation was supplemented with BLEDs irradiation, the amount of vitamin $\mathrm{C}$ was recovered, which was the opposite result to that of Urbonaviciute $e t$ al. This reduction in vitamin $\mathrm{C}$ might be explained by the influence of photon flux density (we examined samples under $54 \mu \mathrm{mol} \cdot \mathrm{m}^{-2} \cdot \mathrm{s}^{-1}$, and Urbonaviciute et al. examined samples under $200 \mu \mathrm{mol} \cdot \mathrm{m}^{-2} \cdot \mathrm{s}^{-1}$ ) [11]. There are also some reports of a study of baby leaf lettuce; one shows no change in the contents of vitamin $\mathrm{C}$ by any LEDs irradiation [27], and the other is reporting the differences occurred by using B-LEDs or green-LEDs irradiation [18]. The influence of photoirradiation on the contents of vitamin $\mathrm{C}$ in plants is a subject that requires further investigation.

Regarding the total amount of tocopherol in dry weight, LEDs irradiated barley showed a lower value than that grown under natural light. In R-LEDs irradiated barley, $\gamma$-tocopherol accounted for nearly $40 \%$ of the total tocopherol. In addition, the total tocopherol in barley grown under RB-LEDs was remarkably decreased compared to that of barley grown under other light sources. It has been reported that $\gamma$-tocopherol, which accumulates in seeds during plant growth, is converted to $\alpha$-tocopherol by the catalysis of $\gamma$-tocopherol methyltransferase in the biosynthetic pathway of tocopherol, and homogentisate phytyltransferase is the factor that controls the amount of total tocopherol $[16,17,28,29]$. Our result can be explained by the fact that R-LEDs ra- diation suppresses the activity of $\gamma$-tocopherol methyltransferase, which is a synthetic enzyme catalyzing the conversion from $\gamma$-tocopherol to $\alpha$-tocopherol.

In addition, it can be assumed that the sharp decrease in the total tocopherol in RB-LEDs irradiated barley was due to the suppression by B-LEDs radiation of the activity of homogentisate phytyltransferase, an enzyme that controls the total amount of tocopherol. Since it can be assumed that R-LEDs and B-LEDs irradiation might be involved in the activation of $\gamma$-tocopherol methyltransferase and homogentisate phytyltransferase, respectively, it seems likely that it will eventually be possible to grow barley leaves that contain a large amount of tocopherol by the combination of various LEDs light sources.

The flavonoids in methanol extract from barley leaves on the $15^{\text {th }}$ day after germination irradiated by each light source were compared by HPLC. The profiles of LEDs irradiated barley were very different from those of barley grown under natural light. Lutonarin, which has been reported to be the main component of the antioxidative activity of green barley, was not expressed in barley grown under LEDs, and the peaks of flavonoid constituents, which were detected after the saponarin peak in natural light irradiated barley, declined in barley grown under LEDs (data not shown). This tendency of reducetion in flavonoids by LEDs irradiation might be due to the fixed wavelength of LEDs. We speculate that the barley quickly adapts to it and is free from stress, and thus it does not need to synthesize these antioxidant components. This may also explain the growth parameters measured in the present study, which showed that LEDs irradiation was more effective than natural light.

SEM examination of leaves on the $15^{\text {th }}$ day after germination irradiated by three different light sources clarified that the density of organization was in the order of natural light $>$ RB-LEDs $>$ R-LEDs. This corresponded to the high moisture content in the leaves of plants grown under LEDs (moisture content RB-LEDs = R-LEDs > natural light), and it suggests that growing barley under LEDs can alter the leaves to enable them to contain more water than can leaves of plants grown under natural light.

Based on our study results, we conclude that the cultivation of barley under LEDs light sources has various positive effects, and that LEDs have the potential to produce more functional material than that grown under natural light. Since barley raised under LEDs grows much faster than usual cultivation, possesses a large amount of amino acid, and is nutritionally rich, the utilization of LEDs as a light source and further research into the combination of various light sources such as far infrared rays and other colors of LEDs will likely be the subject of considerable attention in the future.

\section{ACKNOWLEDGEMENTS}

The authors are grateful to Dr. Hiroki Sakagami, Faculty of Agricul- 
ture, Kyushu University, for valuable comments and support regarding the SEM observation.

\section{REFERENCES}

[1] Benedet, J.A., Umeda, H. and Shibamoto, T. (2007) Antioxidant activity of flavonoids isolated from young green barley leaves toward biological lipid samples. Journal of Agricultural and Food Chemistry, 55, 5499-5504. doi:10.1021/jf070543t

[2] Kamiyama, M. and Shibamoto, T. (2012) Flavonoids with potent antioxidant activity found in young green barley leaves. Journal of Agricultural and Food Chemistry, 60, 6260-6267. doi:10.1021/jf301700j

[3] Okawa, M., Kinjo, J., Hagiwara, Y., Hagiwara, H., Ueyama, H., Nakamura, K., Ishikawa, R., Ono, M. and Nohara, T. (1998) Three new anti-oxidative saponarin analogs from young green barley leaves. Chemical \& Pharmaceutical Bulletin, 46, 1887-1890. doi:10.1248/cpb.46.1887

[4] Ueyama, H., Aotsuka, Y., Okawa, M., Ogura, Y., Ukeguchi, M., Hoashi, K. and Kinjo, J. (2011) Antioxidant activities of lutonarin isolated from young barley leaves. Nippon Shokuhin Kagaku Kogaku Kaishi, 58, 170-172. doi:10.3136/nskkk.58.170

[5] Alam, S., Kamel, S. and Kawai, S. (2001) Amelioration of manganese toxicity in barley with iron. Journal of Plant Nutrition, 24, 1421-1433. doi:10.1081/PLN-100106992

[6] Kocheva, K.V. and Georgiev, G.I. (2008) Changes in foliar proline concentration of osmotically stressed barley. Zeitschrift fur Naturforschung C. Journal of Biosciences, 63, 101-104.

[7] Yang, C.W., Xu, H.H., Wang, L.L., Liu, J., Shi, D.C. and Wang, D.L. (2009) Comparative effects of salt-stress and alkali-stress on the growth, photosynthesis, solute accumulation, and ion balance of barley plants. Photosynthetica, 47, 79-86. doi:10.1007/s11099-009-0013-8

[8] Paulíčová, I., Ehrenbergerová, J., Fiedlerová, V., Gabrovská, D., Havlová, P., Holasová, M., Kopáček, J., Ouhrabková, J., Pinkrová, J., Rysová, J., Vaculová, K. and Winterová, R. (2006) Evaluation of barley grass as a potential source of some nutritional substances. Czech Journal of Food Sciences, 25, 65-72.

[9] Zadoks, J.C., Chang, T.T. and Konzak, C.F. (1974) A decimal code for the growth stages of cereals. Weed Research, 14, 415-421. doi:10.1111/j.1365-3180.1974.tb01084.X

[10] Lee, N.Y., Lee, M.J., Kim, Y.K., Park, J.C., Park, H.K., Choi, J.S., Hyun, J.N., Kim, K.J., Park, K.H, Ko, J.K. and Kim, J.G. (2010) Effect of light emitting diode radiation on antioxidant activity of barley leaf. Journal of the Korean Society for Applied Biological Chemistry, 53, 685690. doi:10.3839/jksabc.2010.104

[11] Urbonavičiūtè, A., Samuolienè, G., Brazaitytè, A., Ulinskaite, R., Jankauskiene, J., Duchovskis, P. and Žukauskas, A. (2008) The possibility to control the metabolism of green vegetables and sprouts using light emitting diode illumination. Sodininkystè ir Daržininkystè, 27, 83-92.

[12] Urbonavičiūtè, A., Samuolienè, G., Brazaitytè, A., Ruzgas,
V., Šabajevienė, G., Šliogerytè, K., Sakalauskaite, J., Duchovskis, P. and Žukauskas, A. (2009) The effect of light quality on the antioxidative properties of green barely leaves. Scientific Works of the Lithuanian Institute of Horticulture and Lithuanian University of Agriculture. Sodininkyste Ir Darzininkyste, 28, 153-161.

[13] Forslund, K. and Jonsson, L. (1997) Cyanogenic glycosides and their metabolic enzymes in barley, in relation to nitrogen levels. Physiologia Plantarum, 101, 367-372. doi:10.1111/j.1399-3054.1997.tb01010.x

[14] Nielsen, A.K., Olsen, E.C., Pontoppidan, K. and Moller, L.B. (2002) Leucine-derived cyano glucosides in barley. Plant Physiology, 129, 1066-1075. doi:10.1104/pp.001263

[15] Møller, B.L. (2010) Functional diversifications of cyanogenic glucosides. Current Opinion in Plant Biology, 13, 338-347. doi:10.1016/j.pbi.2010.01.009

[16] Koch, B.M., Sibbesen, O., Halkier, B.A., Svendsen, I. and Møller, B.L. (1995) The primary sequence of cytochrome P450tyr, the multifunctional N-hydroxylase catalyzing the conversion of L-tyrosine to p-hydroxyphenylacetaldehyde oxime in the biosynthesis of the cyanogenic glucoside dhurrin in Sorghum bicolor (L.) Moench. Archives of Biochemistry and Biophysics, 323, 177-186. doi:10.1006/abbi.1995.0024

[17] Jones, P.R., Møller, B.L. and Høj, P.B. (1999) The UDPglucose: $p$-Hydroxymandelonitrile- $O$-Glucosyltransferase that catalyzes the last step in synthesis of the cyanogenic glucoside dhurrin in Sorghum bicolor. The Journal of Biological Chemistry, 274, 35483-35491. doi: $10.1074 / \mathrm{jbc} .274 .50 .35483$

[18] Samuoliene, G., Sirtautas, R., Brazaityte, A. and Duchovskis, P. (2012) LED lighting and seasonality effects antioxidant properties of baby leaf lettuce. Food Chemistry, 134, 1494-1499. doi:10.1016/j.foodchem.2012.03.061

[19] Pourmohseni, H., Ibenthal, W.D., Machinek, R., Remberg, G. and Wray, V. (1993) Cyanoglucosides in the epidermis of Hordeum vulgare. Phytochemistry, 33, 295-297. doi:10.1016/0031-9422(93)85506-M

[20] Moon, H.K., Park, S.Y., Kim, Y.W. and Kim, C.S. (2006) Growth of Tsuru-rindo (Tripterospermum japonicum) cultured in vitro under various sources of light-emitting diode (LED) irradiation. Journal of Plant Biology, 49, 174179. doi:10.1007/BF03031014

[21] Goins, D.G., Yorio, C.N., Sanwo, M.M. and Brown, S.C. (1997) Photomorphogenesis, photosynthesis, and seed yield of wheat plants grown under red light-emitting diodes (LEDs) with and without supplemental blue lighting. Journal of Experimental Botany, 48, 1407-1413. doi:10.1093/jxb/48.7.1407

[22] Davis, M.H. and Simmons, S.R. (1994) Far-red light reflected from neighbouring vegetation promotes shoot elongation and accelerates flowering in spring barley plants. Plants, Cell \& Environment, 17, 829-836. doi:10.1111/j.1365-3040.1994.tb00177.x

[23] Skinner, R.H. and Simmons, S.R. (1993) Modulation of leaf elongation, tiller appearance and tiller senescence in spring barley by far-red light. Plant, Cell \& Environment, 16, 555-562. doi:10.1111/j.1365-3040.1993.tb00903.x 
[24] Ganjewala, D., Kumar, S., Devi, S.A. and Ambika, K. (2010) Advances in cyanogenic glycosides biosynthesis and analyses in plants: A review. Acta Biologica Szegediensis, 54, 1-14.

[25] Pourmohseni, H. and Ibenthal, W.D. (1991) Novel $\beta$-cyanoglucosides in the epidermal tissue of barley and their possible role in the barley-powdery mildew interaction. Angewandte Botanik, 65, 341-350.

[26] Blumenthal, S.G., Hendrickson, H.R., Abrol, Y.P. and Conn, E.E. (1968) Cyanide metabolism in higher plants: III. The biosynthesis of $\beta$-cyanoalanine. The Journal of Biological Chemistry, 243, 5302-5307.
[27] Li, Q. and Kubota, C. (2009) Effect of supplemental light quality on growth and phytochemicals of baby leaf lettuce. Environmental and Experimental Botany, 67, 59-64. doi:10.1016/j.envexpbot.2009.06.011

[28] Abbasi, A.R., Hajirezaei, M., Hofius, D., Sonnewald, U. and Voll, M.L. (2007) Specific roles of $\alpha$-and $\gamma$-Tocopherol in abiotic stressresponses of transgenic tobacco. Plant Physiology, 143, 1720-1738. doi:10.1104/pp.106.094771

[29] Yabuta, Y. and Shigeoka, S. (2005) Shokubutsu no vitamin E seigouseikeiro no zenyou. The Vitamin Society of Japan, 79, 395-398. 